\title{
Entrepreneurship in Medical Academic: What is its Place in Algeria?
}

\author{
Selma Sakhri* \\ Department of Medical Oncology, Algeria, North Africa

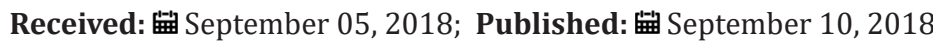 \\ *Corresponding author: Selma Sakhri, Department of Medical Oncology, Algeria, North Africa
}

\begin{abstract}
In Algeria, one of the causes of innovation hindering the medical technology sector is the lack of knowledge and skills in medical entrepreneurship [1-5]. Given this observation, the problematic involves several questions:

a. What is the importance of scientific research, innovation and medical entrepreneurship in developed countries, and in Algeria.

b. Are there start-ups in Algeria?

c. Would we start the process of research, innovation and medical entrepreneurship in Algeria, if so, how?
\end{abstract}

Keywords: Innovation; Lean Start-up; Innovative Clinician

\section{Introduction}

An entrepreneur in the largest economic and social field, is a selfemployed to autonomy, control its affairs and is willing to take risks. Sure, this basis, sociologists like Wright Mills argued that medicine is the apotheosis of an entrepreneurial profession [6], ideological and economic self-sufficiency. Self-sufficiency remains a feature of the medical profession, despite ever greater reliance on technology and the influence of ever increasing regulation of medical practice. Charismatic authority, according to Weber [7], Is another essential attribute of professional personality: the possession of a set of complex knowledge that can directly affect the health and survival of an individual, especially under certain conditions of physical and emotional stress. The legitimacy of this profession gives authority charismatic; Yet this authority can be undermined if it is not often validated by physician behaviour. Personal interest taking risks can represent a major challenge for charismatic authority and requires careful monitoring by each profession, but most of the medical profession. A unique aspect of medicine is that it optimally balances the dynamic between charisma and entrepreneurship [8]. The literature on entrepreneurial universities rarely paid attention to medical universities. However, there are traces of such movements in medical technology, such as biosciences [9]. Some scholars think talking entrepreneurship has nothing to do with medical staff [10], with other members of the domain medical. Mays doctors can be considered entrepreneurs [11]. According to the second perspective, universities must become more enterprising to successfully form such individuals [12].

\section{History of the Medical Entrepreneurship}

Over the past 20 years, entrepreneurship has grown from a defining characteristic of the individual doctor to a precept influential academic medical centres contemporary. The opening of the academy entrepreneurship always offered great opportunities to business enterprises that have realized significant benefits pharmaceutical industries. Only in the last 20 years the academy has realized that the source of a business idea (the inventor of the faculty and the institution of sponsorship) should share with the developer of this idea (industry) its human application: it is beneficial to the inventor, the institution and the entire academic enterprise [13]. At first sight, the entrepreneurial link between academic medical centres and industry seems quite reasonable. Academic physicians and the pharmaceutical and biotechnology industries have a common interest in the advancement of medical knowledge to overcome the disease. Gross intellectual talent academics can naturally be attached to solid business skills of the industry to achieve a successful product development. Ideally, partnerships between academia and industry benefit all parties: the academic medical center inventor and realize financial benefits and get a general recognition of the contribution; the industrial partner 
becomes profitable and meets the expectations of its investors; and patients treated with the invention perform better than previous treatments used. This is particularly true in start-ups starting up that have not yet commercially viable product [14]. Engaging investors in this phase of development of the company is a promotional issue of an idea, and the sooner the investor supports the idea, the more the potential value that will be added to investment will be. Thus, when an academic physician-inventor pass the academic world to the industrial world, it must strive to maintain the highest level of scientific scrutiny and, at the same time, promote concepts that are often scientifically underdeveloped for ensure enough investment.

\section{In the Invention, Transfer towards Commercialization}

The development of new technology, method or medication begins with the invention process and continues with several levels of innovation leading to the application and commercialization. The Algeria remains in a position of technology importing country, know-how and even culture Algerian university scientific. the alarm on this very sad situation. In 1993 a loaded Commission of Experts consider the development issue a diagnosis without appeal. This report highlights the lack of promotion of links between the different sectors involved in research. In this chapter we return to what characterize research and innovation in Algeria while trying to draw a diagnosis of the current situation in Algeria. To do this we will discuss the following:

a) Research organizations and innovation support in Algeria b) Technological poles, intellectual property and technology monitoring activity in Algeria.

c) Diagnosis for research and innovation.

\section{In Developed Countries}

The development of new technology, method or medication begins with the invention process and continues with several levels of innovation leading to the application and marketing (Figure 1). In a masterpiece, Professor Norbert Wiener has advanced the theory that it takes at least four important conditions for an invention becomes a product [15]. The first member (Invention) is the creative process during which many new ideas arise. The second element (innovation): the availability of materials and suitable techniques for validation and execution of the idea. Wiener describes the third member (Marketing):as the need for effective communication between the "philosopher" and "artisan". Finally, the translation of an invention depends on those who benefit financially from the invention by creating economic value (Figure 1). These general concepts are still valid today and provide an excellent roadmap to the invention through several levels of innovation to economic impact. To distinguish the invention from innovation, Fagerberg offers the following description: "Invention is the first occurrence of an idea for a new product or process, while innovation is the first attempt to put it into practice [16]. While there are many definitions of invention and innovation, Fagerberg description is effective and what is that we choose to use our thesis. Our interest concerns the case where the invention comes from academic medical centers.

\section{Invention Innovation Commercialization $>$ Advance}

Figure 1: The steps of the invention to the impact on health care.

The invention is then followed by an initial validation and an application for protection of intellectual property within the university medical center. This sets the stage for many subsequent steps to bring innovation to the invention in clinical use or commercialization. Innovation is a bridge between the university (invention) and industry (marketing). The transfer of a university medical center in the industry should take place at appropriate stages of the continuum of the innovation process. Although there are no clear guidelines to define when this transfer should take place, there are obvious cases where innovation is very complex and should be encouraged in the university medical center before moving to a commercial entity minimize technical risks associated with biology, particularly human biology that cannot be fully appreciated by industry colleagues and the investment community.

This transfer has traditionally taken place after the invention but before that innovation takes place. This model has worked well for innovations in the physical sciences such as chemistry, physics and computer applications where the underlying science is well understood quantitatively. On the other hand, in the experience of these scientists, this transfer model carries much greater technical risks in human biology, especially in the field of diagnostics. It can be argued that academic medical centers, to minimize the risk of failure, should be encouraged to incorporate the invention into innovation space as much as possible in "incubators " in the University Medical Center before moving to industry. In this model, technology risks have been eliminated and the industry will be responsible for the commercial performance of innovation for which the industry is expert. This inevitably reduces the risk of subsequent technology transfer to a commercial partner and maximize value creation and impact on the progress of health care. This is clearly a result desired by all parties involved in the process, and reports to the office of academic medical centers.

In addition, the ability to validate a new technology within the center and further improve its performance measures that increase the value of the invention and therefore the financial benefit to inventors and the university medical center. On the other hand, 
there are at least three key drivers in the industry to maximize the return on investment (ROI) for investors, particularly in start-ups financed by venture capital, to take on this additional risk and enter as early as possible in the capital, innovative process. Sometimes this approach is appropriate and sometimes not. Regarding the three main driving forces.

i. The First Force: Is to minimize the cost of the invention by investing in new idea soon after its conception in a university medical center.

ii. The Second Force: Is to exercise strong control over the structure intellectual property to minimize potential leakage of the latter is more likely to occur in an academic environment $[17,18]$. This is an important factor in shaping the relationship between academia and industry, even after the IP have been authorized by an industrial center with a university medical center.

iii. The Third Factor: Is the relentless time pressure to which the industry works while engaging in the innovation process, especially in companies backed by venture capital $[17,18]$.

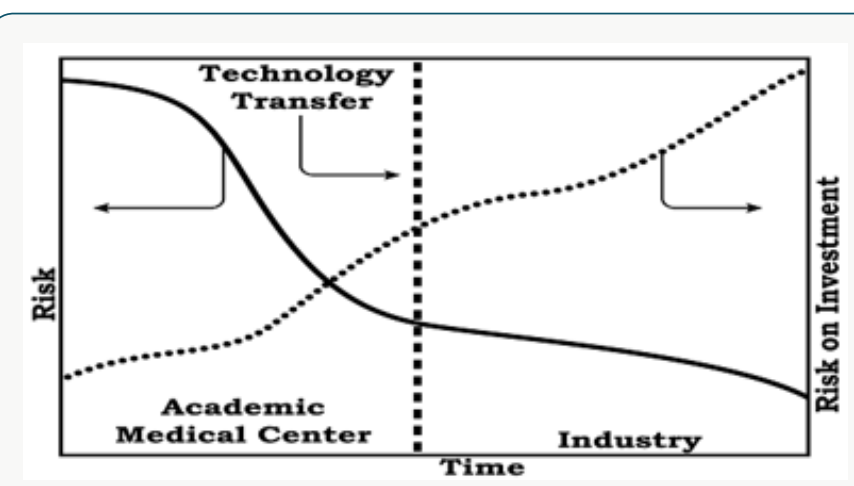

Figure 2: Relationship between risk and return on investment at the university medical center, and the time of transmission technology to the industry.

Although timelines are generally soft and treated as general guidelines in universities, a significant delay in the timelines causes a significant loss of value in subsequent rounds, or worse, the business failure with loss innovation for the care patients. Une hybrid alternative approach to move from academia to industry could be to work with technology innovation companies strategically positioned between the inventor and industry to translate emerging innovations to customers (Figure 2). These companies bring critical expertise in product development, manufacturing, packaging, scaling and others, and mitigate the risk of failure while increasing the value of the initial discovery. In addition, product development is a complex process and requires expertise that generally beyond the scope of an academic medical center. The ability to reduce the risk of failure associated with manufacturing and product development using innovative technology companies may also allow academic medical centers to access alternative sources of funding and more mature than the capital risk. Consequently, the possibility of working with technology innovation companies promises a very rewarding partnership for academic medical centers.

\section{In Algeria}

The situation of research and technological development in Algeria did appear that for several decades, the country remains in a state of technology importing country, know-how and even scientific culture. Witness, the palette of researcher's contribution for meetings and Algerian academics to pull the alarm on this very sad situation. In 1993, a commission of experts to investigate the development issue a diagnosis without appeal, which is still relevant in the current period. This report highlights the lack of promotion of links between the different sectors involved in research, the lack of organization and logistical support the benefit of research at the university, the irrelevance of some research in relation to the needs of society $[19,20]$.

\section{Research Organizations and Aid Innovation in Algeria}

i. Politics of Scientific Research Algeria

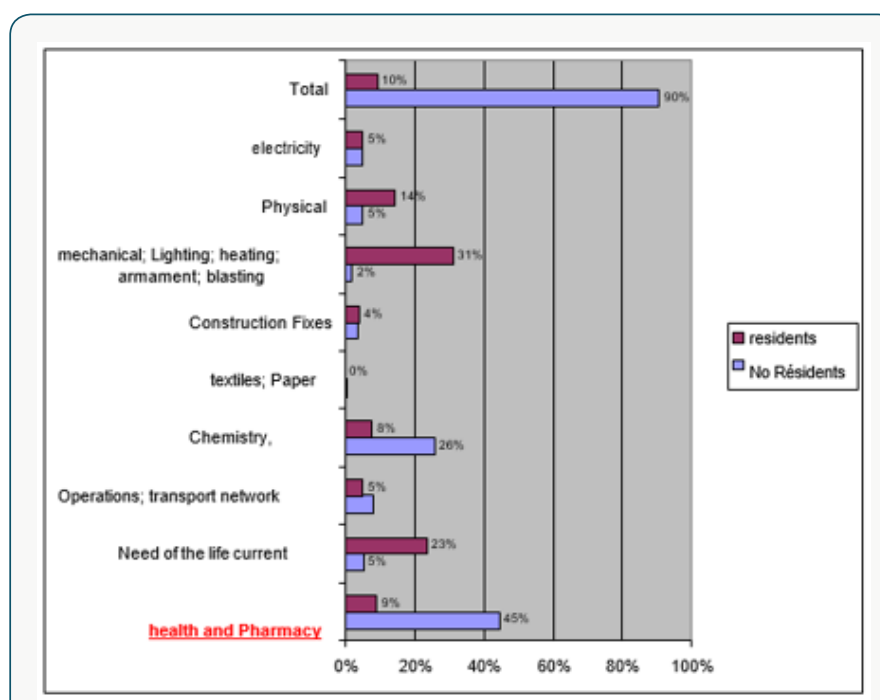

Figure 3: Summary the distribution of applications by type and by area.

The in Algeria search system is relatively new and stammering when compared to developed countries. The creative activities of scientific and technological creation were side-lined. Something that led to a delay of more significant in the technology race. It was only in 1998, found the first attempt that tries to remedy this deficiency through the Voting Law No. 98-11 of August 22, 98, wearing orientation law and five-year program on scientific research and development technology. This law reaffirms that scientific research and technological development are the new priorities, including through the creation of 590 research laboratories in various institutions of higher education (Figure 3). This law is very special because it does not consider all aspects of the lock (no charge notebook obligation results). That said, Algeria has several agencies and broadcasting agencies of research and innovation support and technology transfer. Indeed, the network of scientific research account alone 18 establishments ten (10) research centers, five (5) research units and three agencies 
research, and more research laboratories in various universities of the country [21]. The first fact, which appears clearly in Algeria is that there is not strictly speaking of national research policy in Algeria. The structures in place seems quite bureaucratic with very limited action. Med Best report supports this view by pointing to

For many years, Algeria has set up several organizations and dissemination agencies of research and innovation support and technology transfer (Table 1).

Table 1: Research Institutions Algeria.

\begin{tabular}{|c|c|c|c|}
\hline Organizations & Creation & Dissolution & Replacement \\
\hline National Organization for Scientific Research (ONRS) & 1973 & 1983 & - \\
\hline Scientific Information Center and Technical and Transfer Technology (CISTT) & 1974 & - & CERIST (1985) \\
\hline Superior Council of Scientific and Technical Research (CSRST) & 1982 & - & - \\
\hline units Scientific Research and Technology & 1983 & - & - \\
\hline Research Centers created within the central administrations & 1983 & - & - \\
\hline Office of Scientific and Technical Research (CRST) & 1984 & - & - \\
\hline Economics Research between Applied Development (CREAD) & 1985 & - & - \\
\hline $\begin{array}{l}\text { High Commissioner for Research (UNHCR) Advanced Technology Development Center (CDTA) } \\
\text { Energy Development Center Renewable (CDER) }\end{array}$ & 1986 & 1990 & - \\
\hline \multirow[t]{2}{*}{$\begin{array}{l}\text { Advanced Technology Development Center (CDTA) } \\
\text { Energy Development Center Renewable (CDER) }\end{array}$} & 1988 & - & - \\
\hline & 1988 & - & - \\
\hline $\begin{array}{c}\text { Intersectoral Committees promotion, Programming and evaluation Scientific and Technical } \\
\text { Research }\end{array}$ & 1992 & - & - \\
\hline National Scientific Research Council and Technical & 1992 & - & - \\
\hline Development of Academic Research (ANDRU) & 1995 & - & - \\
\hline National Agency of Valuation Results of Research and Technological Development (ANVREDET) & 1998 & - & - \\
\hline $\begin{array}{l}\text { Algerian Association } \\
\text { Technologies (@2T2) }\end{array}$ & 2000 & - & - \\
\hline
\end{tabular}

a) National organization of the scientific research (ONRS)

It is by Ordinance No. 73-44 of 25 July 1973 was set up the National Organization for Scientific Research (ONRS), with headquarters in Algiers. The ONRS was established as the instrument of execution of the promotion and scientific research orientation policy defined by the Algerian Government and purpose was:

iii. To stimulate and direct scientific research universities and institutes including the provision of grants and contracting

iv. Control science and management of research centers, the fragility of the relationship between industry and science, and the lack of space for research associations or engineering group, etc. [22].

ii. Organizations of Research and of Valorisation of the Research in Algeria 
iii. Facilitate and ensure the publication of studies and research.

iv. To acquire, create, drop or operate any license model or patent.

v. To propose the creation of new research centers.

vi. To promote the formation and promotion of national researchers.

vii. in universities, institutes and research centers through the implementation of appropriate means, including the allocation of allowances and the price of institution.

viii. To perform, Algeria and outside the territory, within the limits of its powers, all studies and work related to its purpose and conducive to its development.

ix. To participate in international scientific activities. This organization, however, was dissolved in 1983, exactly ten years after its creation.

b) Center for Scientific and Technical Information and of Transfer Technology (CISTTT)

The Center for Scientific and Technical Information and Technology Transfer (CISTTT) established in 1974 in the wake of the creation of the ONRS, was responsible for:

i. To gather the scientific and technical information available

Table 2: Distribution of Applications by Type and Field. in Algeria.

ii. Allow scientists Algerian executives and technicians access to the scientific literature and technical world, to study the needs and fill the gaps in scientific literature.

iii. Ensure the interconnection of the Algerian documentary network with foreign networks.

iv. Facilitating the flow of scientific and technical information between issuers and users of this information.

v. Promote training of librarians including familiarizing them with modern methods of information retrieval.

vi. Put at the disposal of national bodies, information resources on the sources of imported technologies, their economics and legal.

vii. Undertake detailed sectoral studies on the technology available in the world, their acquisition cost, business practices concerning those technologies and impact of their transfer to the socioeconomic development of the country;

viii. To ensure, in the field is concerned, the completion of all work or studies to be entrusted by the Ministry of Higher Education and Scientific Research, ONRS, public and Para public organizations and local communities.

ix. To participate in scientific activities Internationals (Table 2).

\begin{tabular}{|c|c|c|c|}
\hline Nature deposits & Non-Residents & Residents & Total \\
\hline \multicolumn{4}{|c|}{ Areas } \\
\hline Health and Pharmacy & 326 & 7 & 333 \\
\hline Need to Everyday life & 38 & 18 & 56 \\
\hline Industrial Techniques Transportation & 58 & 4 & 62 \\
\hline Chemistry Metallurgy & 188 & 6 & 194 \\
\hline Textiles Paper & 5 & 0 & 5 \\
\hline Construction Fixes & 26 & 3 & 29 \\
\hline Mécaniques; Lighting heating Armement Sautage & 15 & 24 & 39 \\
\hline Physical & 37 & 11 & 48 \\
\hline Electricity & 36 & 4 & 40 \\
\hline Total & 729 & 77 & 806 \\
\hline
\end{tabular}

c) Superior Council of Scientific and Technical Research (CSRRT)

In 1982 the Higher Council for Scientific and Technical Research (CSRRT) was created. The Supreme Council's mission is to stop the broad guidelines of the national policy for scientific research and technological development and coordinate its implementation and to enjoy the performance. In this context, it is responsible for:

i. To stop the major options of scientific and technical research which it sets. ii. Objectives and Priorities: To adopt the guidelines of the National Plan of Scientific and Technical Research.

iii. To stop the guidelines of national investment programs for the promotion and development of scientific and technical research.

iv. To assess the results of actions in the national scientific research plan technical.

v. The Council is also responsible for: To stop the general 
guidelines for the preservation policy, recovery and development of the scientific and technical potential national.

vi. To adopt measures concerning the adaptation of executives. organizational scientific research in the various stages of its evolution and its development.

For the realization of scientific and technological development objectives set by the National Development Plan, Decree No. 83-455 of 23 July 1983 authorized the possibility of creation of scientific and technical research units within higher education institutions as well as companies and public organizations. These research units are scientific entities, based execution of research and consist of research teams, one or more laboratories, workshops or other suitable media. They were created to lead the research activities of the scientific program and / or technological encompassing several projects research.

\section{Methodology}

This thesis deals with the identification of the different critical steps of the invention (scientific research) to commercialization, the role of academic medical centers in this process and its impact in Algeria.

\section{A Research Unit is Charged, According to his Vocation}

i. Execute all work studies and research related to their subject.

ii. Promote assimilation, control and acquisition of new scientific and technical knowledge.

iii. Reproduce, in reduced scale, some industrial techniques to solve technical production problems.

iv. To conduct adaptive trials can result in improved production techniques and products.

v. To develop new techniques.

vi. To contribute to the training in the field of research.

vii. Disseminating research results.

viii. To gather and process scientific and technical information related to its purpose and ensure the preservation and dissemination.

ix. Periodically evaluate its work research.

Moreover, funding for research programs of each unit comes: grants from the state institutions and national and international organizations; Research credits of the connecting structure, of product of their activities, contracts, patents and publications; donations and bequests to unit.

\section{Center of Search Created within Administrations}

As part of the implementation of the national plan for scientific and technological development, it can be created According to Decree No. 83-521 of September 10, 1983, centers of scientific and technical research with one or more central governments.
These research centers have overall mission implementation and realization of scientific and technological development programs in the areas that are defined by their decree creation. A such, they are responsible include:

i. To bring together the elements necessary for the identification of research projects to be undertaken and the data for planning.

ii. To stimulate and promote assimilation, mastery, progress and application of science and technology and technological innovation in their field.

iii. To undertake research relevant to their subject.

iv. Periodically evaluate their research and the progress of research in the world.

v. Collect and process scientific and technical information and to ensure the preservation and dissemination.

vi. To use the results of research including ensuring their distribution, their operation and their use.

vii. To participate in the training of managers and technicians research.

viii. In addition, these research centers ensure, each in its field, animation and coordination of research units within the same regulatory authority.

ix. Moreover, the financial resources of these research centers from:

x. Of state subsidies.

xi. Subsidies for local government, business and public organizations.

xii. Grants of International Organizations.

xiii. The product of their activities, contracts, patents and publications.

xiv. Donations and legacies.

xv. Any other resources.

\section{High Commission for Scientific and Technical Research (CSRT)}

This is by decree of 7 July 1984, the Office of Scientific Research and Technology (CSRT) was created. The Commissioner's mission to contribute to the national policy for scientific and technical research and the consolidation of technological independence. It identifies, analyses and prepares all elements necessary for the development and implementation of national policy for scientific and technical research. As part of its overall mission, the Commissioner is specifically responsible for:

i. Prepare the components used to set targets for science and technology policy.

ii. Develop, in conjunction with all sectors, the drafts of annual 
and multiyear scientific and technical research, in view of their integration into national economic and social development.

iii. Develop, in conjunction with all sectors concerned in accordance with national scientific and technical research and evaluation of results achieved, the preliminary draft annual budgets of the scientific and technical research.

iv. Develop with relevant sectors drafts plans and scientific and technical information programs and ensure the implementation and monitoring plans approved.

\section{Center of Research on Scientific and Technical Information (CERIST)}

The Research Center on Scientific and Technical Information (CERIST) was established by Decree No. 85-56 of March 16, 1985. The CERIST inherits the CISTTT activities. he Its mission is to conduct any research on the creation, implementation and development of a national scientific and technical information system.

As such, in an agreed framework and in liaison with the sectors concerned, it provides coordination of scientific and information programs technical.

In addition to the general tasks assigned to it, CERIST shall:

i. To consider and offer all appropriate regulatory measures to ensure the development and promotion of scientific and technical information.

ii. To participate in the establishment and development of a national network of scientific and technical information;

iii. To participate in the creation of data banks in all areas of science and technology in each sector and promote, through its coordination efforts, their access to various users.

iv. Proposing measures that can ensure the rational acquisition and circulation of scientific and technical information nationally to users.

v. To promote the introduction of modern technology such as computers for the collection and processing of scientific and technical information, the development of software systems for automation of the literature and scientific information and technical.

vi. To ensure coordination of the interconnection of the national documentary network with foreign networks in the field of Scientific and Technical Information.

vii. Under the guidance of the Office of the Scientific and Technical Research, CERIST is also responsible for.

viii. Prepare scientific and technical elements projects Avantmaking of scientific and technical information plans.

ix. Ensure editions of Office of the Scientific and Technical Research. $\mathrm{x}$. To participate in the popularization of science and technology in particular in the form of publications and scientific films.

xi. To contribute to the exploitation of results of scientific and technical research in the context of its Scientific and Technical Information Mission.

xii. Ensure any research or study relating to this object.

\section{High Commissioner for Research (UNHCR)}

The Office of Research (UNHCR) was established by Decree No. 86-72 of 8 April 1986. He had overall responsibility for implementing, following the decisions and priorities set by the Government, the national research policy. He was also responsible for implementing the national policy in the field of renewable energy.

As part of its overall mission, UNHCR was responsible for:

i. To identify and propose, in connection with the relevant sectors, national research programs.

ii. Develop, in conjunction with the relevant sectors, annual and multiyear research programs of fixed and integrated into the national development plan.

iii. Coordinate, monitor and harmonize, in connection with the relevant sectors, the implementation of programs and orders research plans.

iv. To support the implementation of programs and research plans when the nature and importance of the area require.

v. Undertake periodic evaluation of program implementation and arrested research plans and to report to the Government following established procedures.

vi. Proposing any regulatory and financial measures that would promote research activities, improve the organization and develop and profitable.

vii. Scientific and technical potential especially in institutions Higher education.

viii. To organize, standardize and coordinate, processing, exploitation.

ix. and the dissemination of scientific and technical information.

$\mathrm{x}$. To implement in relation to the sectors concerned, measures to assimilate, develop and disseminate the results and research findings in the context of training, information, innovation and extension.

Four years after its creation, UNHCR was dissolved on 1 December 1990.

\section{Center of Advanced Technology Development (CDTA)}

The Advanced Technology Development Center passes Commissioner of the Research Unit of the New Energies status to 
that of Center for Research and Development by Decree No. 88-61 of March 22, 1988.

HE then called Advanced Technology Development Center (CDTA), under the supervision of the High Commissioner for Research. Its main tasks related to the management of the shares of R / D, training, service delivery, and scientific and technical information in the two sub-sectors, namely cyber sub-sector which includes laboratories systems architecture, robotics, microelectronics, software engineering and sub-sector of ionized media which includes laboratory lasers, plasmas and fusion thermonuclear. In the decade since its inception, CDTA recorded nearly 170 entries of its researchers at international conferences and 120 other national conferences. On the other hand, there were 44 publications in international journals of high level researchers from its various laboratories. CDTA nearly 75 thesis defenses Magister since 1988. In addition, the Center allowed his research staff follow doctoral programs abroad.

\section{Intersectoral Committees of Promotion, of Programming and Evaluation of Scientific Research and Technical:}

It is the Executive Decree No. 92-22 of 13 January 1992 which focused on the creation, organization and operation of cross-sectoral promotion boards, programming and evaluation of scientific and technical research (CIPPERST) with Minister for research. These committees are responsible for the promotion, coordination and evaluation of research and technological development (or) national programs they are responsible. As such, they are particularly charged:

i. To study and propose research and development programs and appropriations, ways and means of their realization.

ii. To organize cooperation between the administration, research organizations and economic institutions and companies directly or indirectly involved in the research area considered to ensure a better coordination and optimal use of resources.

iii. Foster collaborative and interdisciplinary research and propose the necessary measures for its development.

iv. To study and propose actions promoting the results of the research;

v. Ensure the organization and development of a system of information exchange and scientific and technical documentation.

vi. To contribute to the updating of the inventory of scientific and technical potential and propose measures for its rational and optimal use.

vii. To participate in the coordination of national programs related cooperation activities which it is responsible.

viii. Evaluate the research programs and establish detailed activity reports in its field and on the operation of research facilities.

ix. Establish outlook reports for the continuous updating of research and development programs technology.

\section{National council of Scientific Research and Technical}

The National Council for Scientific and Technical Research (CNRST) was created by Executive Order No. 92-23 of 13 January 1992. The council's mission is to stop the broad guidelines of the national policy for scientific research and technological development and coordinate its implementation and to assess its performance. In this context, it is responsible for:

i. Determine the major options of scientific and technical research.

ii. To adopt the guidelines of the national scientific and technical research.

iii. To assess the results of actions under the national plan for scientific research and technical.

iv. The board is also responsible for: To stop the general guidelines for the preservation policy, recovery and development of the scientific and technical potential national.

v. On the measures relating to the adoption of organizational frameworks for scientific research in the various stages of its evolution and development.

\section{National Agency for Development of the Research University (ANDRU)}

The National Agency for the Development of Academic Research (ANDRU) was created by Executive Decree No. 95183 dated 2 July 1995. The ANDRU's mission is to stimulate and support the development and enhancement of research activities within the framework of national research programs as defined by current regulations and located in university teaching and research institutions. As such, it is specifically responsible:

i. Develop annual and multiannual programs and ensure their implementation.

ii. From to launch and monitoring of tenders as part of its programs.

iii. To proceed with the establishment of monitoring mechanisms and evaluation of research activities which it is responsible.

iv. In finance, through agreements and / or contracts, research projects selected.

v. To promote and boost support mechanisms and circuits and administrative and financial management of university research.

vi. Ensure the dissemination and exploitation of research results which it is responsible. 
vii. To contribute to the organization and taking material and financial support of national and international scientific events related to its field of activity.

viii. To extend his assistance, technical and financial plan for the acquisition of equipment and scientific literature.

ix. To promote and support training programs, training and retraining related to his field activity.

\section{National Agency of Valuation Results of Research and Technological Development (ANVREDET)}

It was in 1998 that was created the National Agency for Valuation of Results and Technological Development (ANVREDET). The ANVREDET aims to implement in relation to the structures and bodies, the national strategy of technological development, including the transfer of research results and recovery. As such, she is responsible include:

i. To identify and select results the Research to develop.

ii. To contribute to better efficiency in the exploitation of results research and organization of the systems and methods of recovery of such research to promote development and technological innovation.

iii. Develop and promote cooperation and exchanges between the research sector and user industries for the recovery and the transfer of technologies and new knowledge, particularly towards SMEs.

iv. To encourage and support any initiative aimed at developing technology and introducing innovation actions.

v. To assist inventors in the care benefits for prototyping, studying markets, finding partners and patent protection.

vi. Organize the technology watch, including the establishment of observatories and distribution networks technology.

\section{Algerian Association for the Transfer of Technologies (@ 2T2)}

The Algerian Association for Technology Transfer is a scientific association governed by Law No. 90-31 of 4 December 1990 that was created in 2000. It attaches intended to provide a meeting place and constitute an active, relays to integrate the necessary synergies in the effective transfer of techniques and technologies, and in:

i. Providing a dynamic interface between knowledge tanks available in universities, colleges and research centers in Algeria or abroad, on the one hand and potential users, on the other share.

ii. Creating through new information and communications technology forum as a virtual forum for Algerian scientists regardless of their place of residence who wish to contribute to the promotion of technology. iii. Setting up a framework and exchange of knowledge and / or expertise.

iv. This association aims the following objectives: Studying ways of valuing R \& D work carried out in Algeria or abroad may have opportunities and potential applications of the country.

v. Think about the problems concerning the involvement of the scientific community abroad and national expatriate skills in general.

vi. Contribute to the transfer of emerging technologies and their integration in particular, disseminating successful experiences in adapting and integrating technologies.

vii. Promoting University-Industry linkage by establishing bridges for reconciliation between researchers and industry.

viii. Contribute to the extent of its resources to the implementation of programs help

ix. Governmental and nongovernmental (UNDP, UNESCO Specialized agencies) for the promotion of technology.

x. Cooperating with various specialized networks in the world affected by the transfer of technology and promotion of technology in general.

xi. Organize for its members and / or the public lectures, workshops, seminars, symposia, conferences on topics related to its purpose and continuous training cycles on current topics relating to technology and promotion of research in general.

xii. Work towards the dissemination and popularization of new technologies by focusing on their impact socioeconomic.

\section{The Center for Research in Applied Economics for Development (CREAD)}

Created in 1975 under the leadership of Professor A Benachenou under the symbol of CREA, it took its current name in 1985 through the enactment of Decree No. 85-307 of 17 December 1985. Under the supervision of the Ministry of Education and Scientific Research (MESRS), its mission is:

i. Conduct theoretical research on economic development.

ii. To study the social and economic conditions necessary to strengthen cross-sectoral integration, creative and technical skills and effective management at the macro level and microeconomic;

iii. To provide support to economic operators and decision makers in the areas of its skill.

iv. To establish and maintain a body of researchers abreast of the latest developments in its fields of competence particularly with ongoing cooperation with the scientific community International. 


\section{Evaluation of Structures of Promotion and of Support Innovation}

The aim of all scientific research policy and technical development is to promote conditions for a more effective dissemination and exploitation of research results as well as the assimilation of research products by the socioeconomic sector. Thus, any action of promoting the results of research and economic development is presented in two main parts:

i. A first component on dissemination, communication and exploitation of results research.

ii. A second phase, which covers the transfer of products of research and development technical.

Regarding the first component, the program for the promotion of scientific research and technical development, advocated the establishment of an incentive system for the publication, as well as ways of typesetting and printing. On the second part, namely the transfer of knowledge to industry, the report recommends:

iii. Promote the organization of institutional linkages between research and production through the implementation of development unit and promotional expertise, knowledge and products of the research.

iv. Ensure the expansion of technological innovation through the implementation of laws regarding the awarding of honors and awards to top researchers on the basis of their results.

98-11 The law also provided provisions for value engineering capacities, and improve national capacity-control, adaptation and reproduction of imported technology through mostly.

v. The creating valuation structure and technical and economic studies within higher education institutions and research.

vi. Apart from the creation of the recovery agency of the results of research and technological development in 98, the valuation process in Algeria has not experienced a notable development.

vii. Faced with the reality on research products resulting from scientific research to the market, the project on scientific research and technological development lists a few measures to be implemented urgently to remedy this situation like of: Implement strategic management by the orientation of the creativity of Algerian researchers to the themes that have relevance economically and register the valuation component in the definition of research projects.

viii. Enhancing synergies and economies of scale through the favouring of partnership and dialogue between researcher's innovation.

ix. To provide operational strategy, shared risk, innovative projects involving financial structures, guarantee funds and the organizations supporting entrepreneurship (ANSEJ, ANDI, CNAC). $\mathrm{x}$. Encourage the establishment of the incubator device at the companies.

Currently, it seems very clear that the three structures that are meant to work in coordination to know the ANDRU to finance part of scientific research, the ANVREDET for the valuation component of research results, and INAPI for appearance protecting inventions, are completely disarticulated bodiess working in closed vessel with no ties partners. Thus, it emerges, that no specific measures could make such acclaim in scientific research and technological development and those despite the existence of institutions dedicated to this mission. This observation is added, the nagging problem of funding and support for innovative projects. The Algeria brand in this field far behind, with almost no investment banks and venture capital firms, a poorly developed capital market, which greatly hamper the development of innovative activities.

\section{The Property Intellectual}

There are Algeria agency responsible for industrial protection and patent registration. This is the National Institute of Industrial Property Algerian (INAPI). This public industrial and commercial nature was created by Executive Order No. 98-68 of 21 February 1998, replacing the Algerian Institute of Standardization and Industrial Property created in 1973 under his inventions related activities, and the Register of the National Trade Center (NRC) in respect of its activities relating to trade marks, industrial designs and appellations of origin. INAPI implements national policy proprietary particularly protects the moral rights of creators.

It is for this reason that it is responsible for:

i. Ensure the protection of industrial property rights.

ii. Stimulate and strengthen the creative and innovative capacity that meet the technical requirements of national, through measures of material and moral incentives.

iii. Facilitate access to domestic users, industries, research institutions, universities, etc, the technical information contained in patent documents, identifying, selecting and providing this information constituting alternatives to a given technical and sought by such users.

iv. Improve the conditions under which foreign technology is imported into Algeria through analysis, monitoring and procedures to acquire foreign technology involving intellectual property rights and royalty payments on these rights abroad.

v. To promote and develop the capacity of Algerian companies to facilitate free trade relations unfair competition, protecting the public against confusion about the origin of products, services and companies' marketing and preventing against errors resulting from such confusion.

vi. As part of its mission, the Institute provides: The examination of applications for protection of inventions, registration, and, where appropriate, their publication and issuance of titles of 
protection, set by regulation;

vii. The examination of trademark registration applications, industrial designs and origin and their publication;

viii. The registration of acts affecting industrial property rights and licensing agreements and assignment of rights.

ix. The participation in the development of creativity and strengthening its implementation through the promotion of innovative activity.

x. The implementation of any step to ensure control of the transfer of assimilation techniques in its aspects of industrial property.

xi. The application of provisions of international conventions and agreements in industrial property and, where applicable, participation in their work.

The Institute makes available to the public any documents and information related to his field and thus a database of industrial property. However, despite the efforts, the number of registered patents remains weak and are mostly of foreign origin. This reflects the weak national capacity for innovation and invention and efforts of R / D (research and development) nationwide. It is therefore necessary to rectify this situation by taking appropriate measures for stimulating R / D (research and development) and innovation by an incentive scheme Institutionalized, particularly the protection of the rights of researchers by filing patents, copyrights, inventor certificates or innovative.

\section{The Activity of Technology}

Technology Watch is the observation and analysis of the scientific, technical, technological and economic to detect threats and seize development opportunities. In a context of globalization and internationalization of competition, it seems obvious that creativity is not enough, it is necessary to know what the competitors. And in this sense, technology monitoring activity is paramount to oversteer in a turbulent environment. However, the technology watch function remains unknown in Algeria.

\section{Diagnosis in Research and Innovation Indicators Algeria}

Assessing innovation in Algeria through the analysis of a few indicators, which are borrowed from the consulting model of science and Canadian technology.

\section{Indicator 01: Number of Patents Received}

The patent is one of the forms of outputs (exits) of the innovation process in organizations. he means a temporary monopoly that provides protection and the inventor an exclusive right over the invention. This makes him one of the most relevant indicators to measure scientific activity and technology of a company, institution or country. The bar chart shows that in terms of deposits healthy patents, non-residents outnumber residents. For $2010,97 \%$ of deposits are made by non-residents and the rest is up to national. This demonstrates the interest of non-residents for this type of protection of innovations and low innovativeness of organizations in Algeria. Furthermore, the distribution of the nature of the deposits by field of invention shows that the field of health, pharmacy is valued patent application material.

Indicator 02: Proportion of Research in The Medical Universities Funded Industry

HE Algeria does not exist in a research funding system in medical universities in the industry, it is essential to note that entrepreneurship in these universities is a key component in any system health innovation, working in collaboration with businesses and industries phamaceutique. First, it allows to provide the labour market with skilled labour and specialist capable of meeting the challenges of innovation. Secondly, the university, through various studies and research publications contributes to the advancement of science and knowledge in various economic fields.

Indicator 03: Expenditure of Academic Medical Research as \% of GDP

Any innovation system that aims to be efficient is focused on basic research. The numerous publications and research articles fuelling the innovation capacity of an economy. According to the draft law on scientific research and technological development 2006-2010, the share of GDP (gross domestic product) devoted to research expenditure is expected to reach 1\% in 2010. However, it is still far from this goal by 2017 .

\section{Indicator 04: Number of Medical Publications:}

Medical publications (articles, research notes, etc.) from industrial and institutional (universities, research centers) enable to evaluate the overall effort by a given region or country in the production of knowledge and learning. This indicator provides information on the innovation capacity and the degree of absorption knowledge. According to the survey conducted by the Thomson Reuters group, scientific research remains very low in the MENA region (Middle East and North Africa). For 2009 the number of scientific publications amounted to 3200 publications for Algeria against 4200 for Tunisia and 10,100 to Egypt. In publications per number of inhabitants, Algeria produced 50 publications per million inhabitants. It is thus, surpassed by Tunisia which produced 170 publications per million inhabitants.

\section{The Start-Up Entrepreneurship Medical}

In Algeria, the great difficulty the doctor academism, it is the operation rigid of the academic institutions teaching and research. Unlike other developed countries that have long valued the wealth of medical research. The world scientist escapes not at the competition economic and the research will play henceforth a major role in the "new economy ". In this chapter we will examine the perspectives of start up in Algeria, as well as the different technological poles. 


\section{In Developed Countries}

the health sector start-ups have grown dramatically in recent years. The boom is the result of health reforms that disrupt business models, an aging population, this requires more (and better) care, and adoption of technology - such as mobile devices in the medical field.

\section{In Algeria:}

\section{a) Overview of Technological Poles Algeria}

At a time, when talking about national innovation system; dynamic clustering and competitiveness policy in developed economies, to go further in the dynamic creation of knowledge, creativity and innovation, Algeria struggling to implement this junction in the universities. Thus, despite the measures announced in the 2006 bill in 2006-2010 on the establishment of regional technology parks near universities and industrial and agricultural centers, field observation reflects a different reality. Indeed, currently, there is only one project in Algeria cyber park or technological cyber called Sidi Abdellah Park. It is the first technological pole in the country, it was launched in 2001 and focuses on three districts: the technopolitan park, the innovation district and support structures. The Sidi Abdellah Cyber Park will include eventually all types of companies, whether local or foreign offering products and / or services including related information and communications technology (TIC).

The technopolitan park will cover aspects related to production such as manufacturing components. he also includes activities related to the distribution, marketing products and services. technology transfer centers, incubators, nurseries, aid agencies and small business observatory (TIC). The innovation district meanwhile, include service centers, research and development of private or public companies, universities and consortia or other independent research laboratories in the field of new technologies. Apart from this project, the launch in Algeria a new as scientific agglomeration in the medical field: the biotechnology cluster Which will be realized in 2020 in the new city of Sidi Abdellah (Algiers), an Algerian-US partnership in the field of biotechnology will benefit in the first place, and the patient who will access to the best performing pharmaceutical, even that contribute to the development of scientific research on the one hand and the growth of the pharmaceutical industry, on the other.

\section{b) Proposal Recommendation}

Academic medicine has always been an important driver of innovation, advances in fundamental research forms the basis of health care innovation. Academic medical centers (MACs) have the potential to be leaders in the era of reform the delivery of health care, but most have not yet shown their commitment to innovation in the delivery of services. Several institutional factors impede innovation in the provision, including the lack of adequate training in the design and implementation of new models and the lack of established channels for advancing academic career outside of research. In this chapter we offer two initiatives to boost innovation academic medical centers: institutional program of "innovation incubator" and a clinician innovative career paths coupled with innovation training programs. It exists Algeria in many ways to cultivate innovation in health care, but today Entrepreneurship is a neglected engine of innovation in academic medical centers (AMC). The development of an entrepreneurial culture should be a significant impact in these institutions. We offer two solutions for these centers, whether (public or private). They must adopt to develop their own entrepreneurial innovation culture.

i. An institutional program "Innovation incubator"

ii. Create a new training program career.

iii. Clinician innovative (ICs)

\section{Incubation Programs in Academic Medical Centers (AMC)}

An innovation incubator in (AMC): (academic medical centers) is a program that cultivates the rapid transformation of ideas into products or value-generating services that benefit patients. Incubators are natural tools for the cultivation of creative professionals working in (AMC). These latter should attract competent people in various professional areas of health that are often required to have an impact on health care. Incubators could offer new creativity in (AMC) that help clinicians and researchers to turn their ideas not in publications but products and services volutids. La channelling these ideas through an incubator will have a triple victory for (AMC) because:

i. The (AMC) can benefit financially through license fees, royalties or equity investments in technology.

ii. The Clinician innovators can develop and scale new ideas faster.

iii. Patients can get faster access to innovations that can improve their lives.

In addition to these three main advantages, the incubator approach can also benefit from two other key missions (AMC) it is the research and education. Incubators can provide a rich source of academic research opportunities to evaluate different approaches and innovation enable (AMC)differentiate as leadership centers on innovation. Similarly, an incubation program can create many additional educational opportunities to enable teachers and students to get involved in entrepreneurship, program evaluation and project management.

\section{Creation and Management of a New Incubator in (AMC)}

Key resources for incubators in its centers are knowledge their clinicians, combined with the wealth of available clinical data observed by his last. However, its centers lack of innovation in methodology of training programs, so that clinicians are not prepared to take advantage of their ideas and do not efficiently produce solutions to these problems. We offer the following 
adaptation of guidelines on best practices for incubation programs as a starting point for the (MAC): An incubator in these centers must be composed of the following services and resources: experienced entrepreneurial consultants, software developers, legal advice, support fundraising and networking with other innovators (Figure 4). The entrepreneurial advisors must offer a monitoring (support) which continuously inculcates skills and innovation comes to the clinician -innovator (CI) even after the end of the incubation process. Access immediate software developers is key to the rapid development of functional prototypes and can serve as a potential source of technical co-founders for startups that could evolve from the incubator. Legal advisers help to understand the issues of incorporation, licensing, financing and conflict of interest. The fundraising channels help secure internal and external investments to help start-ups emerging incubators (AMC) to rapidly increase their impact. Finally, the networking activities facilitate collaboration between (CI) (innovator clinician) and potential partners, customers, co-founders and investors.

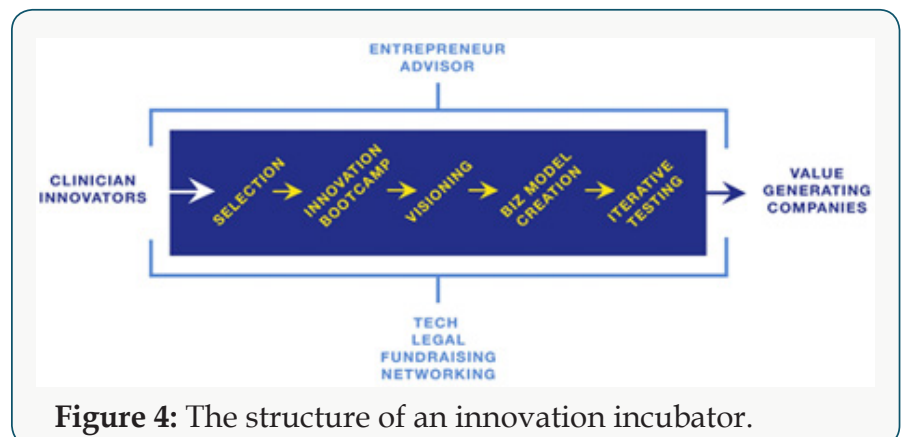

The process of starting an incubator begins with the selection of (CI) participating in an innovation workshop to teach them the basic principles of innovation. With the help of their advisor entrepreneurship, clinicians then do a series of exercises to identify the vision and the goals they are trying to achieve through innovation and their approach to achieving this vision and the specific products or services they create through this approach. After viewing and set innovation goals, entrepreneurship counsellor helps (CI) create a draft business plan to guide their innovation. The business plan presents a series of assumptions made by (CI) about the end user of the problem, unique way. The proposed solution solves the problem and the scaling approach of the solution. The business plan is continually evolving as new results stem from testing the assumptions of the plan. Incubation in (AMC) East ideal for software development. -The end of the incubation process is a product or a commercial service. The next logical step in the growth of start-ups is to pass the incubator innovation activity in these centers and to Many independent health incubator programs (creation of new start-up health exp (the digital).

\section{The Clinician Innovative Career}

Clinicians are essential to the success of an incubator program to support innovation. However, (AMC) (academic medical centers) do not help enough clinicians to advance their academic careers, it would be difficult to convince clinicians to devote more energy to an incubator project. To recognize the contribution of successful innovation in the health care system, (AMC) should create jobs and manage the clinical career innovative. The measure of success in this direction should be based on contributions to successful projects that could be measured in various ways, including Return on Investment (ROI) the savings generated, or venture capital raised rather than on the volume of publications. Incentives for career pathways (CI) should exist at all levels of training, from undergraduate level to level faculty. From an administrative standpoint, the track (CI) is not necessarily more complex than the track Traditional clinical researcher. Clinicians interested in track (THIS) can devote a certain percentage of their time on innovation projects which should initially be supported by clinical department, as young researchers. As an alternative to the departmental funding, support of investors, donors or foundations focused on the social impact could subsidize innovation projects. Unlike traditional clinical research programs, time spent for the (CI) would be used to turn ideas into action. With more experience and a roadmap, teachers with successful projects should eventually be able to support themselves through affiliated business ventures or subsidy mechanisms such as associative subsidies or small business innovation research.

\section{Training in Clinical Innovation}

Ripening (CI) within the incubation system must be strengthened through rigorous training in innovation that complements traditional medical and specialized training. Training in innovation requires exposure to new business practices currently in academic medicine. A fundamental innovation practice is: Thinking Lean Start-up (LST). The Thinking Lean Start-up is a management process that aims to create a minimum viable product (MVP), an intervention with the least necessary features. Advantages are:

i. Reducing the time to put on the market.

ii. Reducing development costs.

iii. The ability to have user feedback quickly other than those related to a prototype.

iv. Confront quickly to market realities.

\section{Another Practical Innovation}

The BML (Build-Measure-Learn) is a continuous process of construction of a prototype, testing and measuring the impact of the invention. Advantage use of LST (Lean Start-up Thinking) as basic methodology for the incubation in the (AMC) of reference for the end user i.e. the patient. The LST will minimize costs and optimize clinical outcomes. The goal of final LST is creating a product or service that is based on the three pillars of quality improvement to achieve "quadruple" objective:

i. Improving quality of care.

ii. The product must be sustainable. 
iii. Improve patient satisfaction.

iv. Lower the costs.

\section{Challenges}

The funding, whether public or private, innovation is a challenge for the future. Upstream, it is necessary to provide the means for research; and then, it is to ensure access to advances generated at the entire population, which represents a high cost to the community. In this chapter we will demonstrate how to overcome the financing challenges in the public academic medical center and private, and the role of creativity of a clinician in the process of technological innovation.

\section{Overcoming Challenges}

Significant challenges must be overcome to a Character Academic Health Center can create incubators and training programs for effective innovation. The most urgent problems are the creation of a culture that accepts innovation for delivery system as a research equally commendable that clinical research. These challenges raise questions about how the promotion of business "for profit" within a state body as (AMC) can always match the nonprofit mission. A non-profit designation to a legal status that enjoys certain tax breaks, while profit status as (Hospitals private) allow greater flexibility in receiving the investment. While the first should focus on the mission, it can also be focused on the mission and more financial incentives to scale.

\section{Harnessing Creativity}

Our proposal for incubators prompt clinicians to use their creativity to help their institution to provide health care and the extend beyond the walls of their system through a consumer-driven growth. Naturally, this can be a change of culture marked for many medical centers (Public and private) to undertake. And promoting entrepreneurial innovation by these centers will allow them to enjoy the changing reimbursement environment.

\section{Perspective}

The new technology creates a potential for innovation. To realize this potential, (AMC) must take the lead and adopt a risktaking which is difficult in our traditionally conservative culture of entrepreneurial medicine. The mind may be associated with an efficient and responsible manner to the patient, this spirit can become a real storm of innovation that can bring our health care system to meet the fourfold objective.

These centers have to play an increasing role in the innovation and development of new devices, drugs and applications. Arguably innovation is essential in these centers. Moreover, the role of these centers is not only to take care of patients, but also to advance healthcare by bringing these innovations to the bedside.

The innovation process between invention and commercialization (application) is essential to the progress of these academic medical centers, and this process must be properly integrated into the educational curriculum of these centers that either state or private.

\section{Result}

The Lean Start-up approach and the creation of ClinicalInnovative Pathways in Academic Medical Centers (CMAs) are the solution to this problem, challenging physicians to go beyond their comforts to acquire knowledge about entrepreneurship in the medical sector, which aims to optimize care, reduce health costs and improve the patient's quality of life.

\section{Conclusion}

The process of innovation between invention and marketing (application) is essential to the advancement of academic medical centers, and this process must be properly integrated into the educational curriculum of these centers whether state or private. The doctor has a central role to play in the innovation process. But if resources are developed to encourage this role is teaching medical entrepreneurship which is the most promising aspect. Because if trained specialists have a key role to play in innovation, it is in the ranks of medical students of today will come the technological revolution of tomorrow. Training programs innovation in academic medical centers offer resources for doctors and other professionals wishing to develop an idea in the field of medical technology. Each program has its own characteristics, but they have in common to bring in medical technology innovation to medicine academic. This allows to combine two objectives:

i. Guiding innovation to problems that are a real clinical need by integrating more important for clinicians and Earlier in development, while promoting a multidisciplinary academic and industrial collaboration.

ii. These programs and centers allow doctors in training to become aware and familiar with the innovation and creation of new devices and offer them, if they wish, a structured learning curriculum.

\section{References}

1. Albert P, Bernasconi M, Gaynor L (2002) Incubators, emergence of a new industry: comparison of players and their strategies (France, Germany, United States) research report cream Sophia Antipolis, ministry of economy, finance and industry.

2. Lamarcq 1 (2007) Social Entrepreneurship: Towards an Alternative Management, Memory Carried in The Master 1 Management Sciences.

3. (2015) Innovation: intellectual capital and innovation management. Editor: upper beck 2(47): 212.

4. Sieqel RL, Miller KD, Jemel A (2017) Cancer statistics. Ca cancer J clin 67 (1): 7-30.

5. (2018) Algerie press service.

6. Mills CW (2002) White Collar: The American Middle Classes. New York, USA.

7. Angell M (2000) Is academic medicine for sale? N Eng J med 342(20): 1516-1518. 
8. Stossel TP (2005) Regulating academic-industrial research relationship - solving problems or stifling progress? N Eng J med 353(10): 10601065.

9. Kemp MW, Newnham JP Chapman E (2012). The biomedical doctorate in the contemporary university: education or training and why it matters. Higher education 63(5): 631-644.

10. Gibb AA, Hanno P (2006) Towards the entrepreneurial university? International journal of entrepreneurship education 4: 73-110.

11. Khanna S (2016) A journey from surgeon to surgeon contractor clarion. International multidisciplinary journal 5(1): 1.

12. Loxley, Seery (2012) Studies in Higher Education 37(1): 3-17.

13. Joseph Loscalzo Md (2007) Entrepreneurship in the Medical Academy. Circulation 115(12): 1504-1507.

14. Sharam Tofighi (2007) Academic Entrepreneurship in Medical University. International Review 58: 1-2.

15. Wiener N (1993) Invention. Mit press Cambridge Massachusetts.
16. Fagerberg J, Mowery, DC, Nelson RR (2004) the Oxford Handbook of Innovation: Oxford university press, UK, p. 1-26.

17. (2007) Innovation. Wikipedia.

18. Loscalzo J (2007) Entrepreneurship in the medical academy: possibilities and challenges in commercialization of research discoveries. Circulation 115(12): 1504-1507.

19. Moses H Braunwald E, Martin JB, (2002) Collaborating with industrychoices for tea academic medical centre. N Eng J med.

20. Khelfaoui H (2001) The Science in Africa At Dawn Of 21st Century: The Science In Algeria - $3^{\text {rd }}$ Part: Professions, Institute Of Research For The Development (IrDA La France), Commission European. Ministry French of the Business Foreign, p. 2.

21. (2006) Ministry of Higher Education and Scientific Research (61): 2122.

22. Anima (2005) Network Euro-Mediterranean of the Agencies of Promotion of the Investments. The Mediterranean Smart: Innovation, Poles Technological and Attraction of Investment in Notes Investments International / Marseilles Innovat Ion, p. 35.

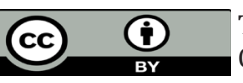

This work is licensed under Creative Commons Attribution 4.0 License

To Submit Your Article Click Here:

Submit Article

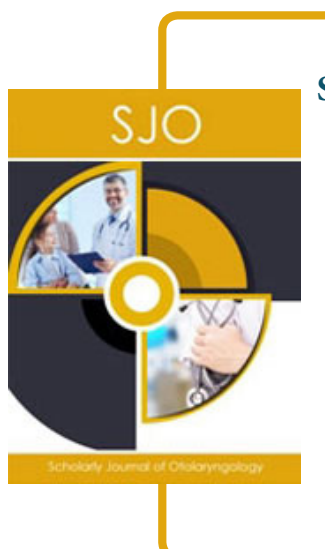

\section{Scholarly Journal of Otolaryngology}

\section{Assets of Publishing with us}

- Global archiving of articles

- Immediate, unrestricted online access

- Rigorous Peer Review Process

- Authors Retain Copyrights

- Unique DOI for all articles 